UDC 342.4:347.471

Submitted: 20.05.2019

LBC 67.400 .4

Accepted: 20.06.2019

\title{
THE VALUE OF CONCLUSION BY THE RESULTS OF PUBLIC EXPERTISE
}

\author{
Anna A. Goncharova \\ “Amulex" National Legal Service, Voronezh, Russian Federation
}

\begin{abstract}
Introduction: public expertise is the competent participation of citizens in the management of state affairs and has great potential in improving the quality of decisions and regulations. Currently, however, the conclusion by the results of public expertise is a recommendation. In this regard, it is important to understand the significance of the opinion on the results of public expertise. The purpose of this paper is to determine the value of the conclusion based on the results of public expertise, using the ideas of divisive democracy. Methods: the methodological framework for the study is a set of methods of scientific knowledge, among which the main ones are the method of analysis and the formal logical method. Results: some practical recommendations for improving the legal regulation of public expertise have been developed. Conclusions: the procedure of public expertise should be supplemented by a mandatory stage, which will be the coordination and discussion of the results of public expertise.

Key words: deliberative democracy, public control, public expertise, independent expert, public control.
\end{abstract}

Citation. Goncharova A.A. The Value of Conclusion by the Results of Public Expertise. Legal Concept, 2019, vol. 18, no. 3, pp. 97-100. (in Russian). DOI: https://doi.org/10.15688/lc.jvolsu.2019.3.14

УДК 342.4:347.471

ББК 67.400 .4
Дата поступления статьи: 20.05.2019

Дата принятия статьи: 20.06.2019

\section{ЗНАЧЕНИЕ ЗАКЛЮЧЕНИЯ ПО РЕЗУЛЬТАТАМ ОБЩЕСТВЕННОЙ ЭКСПЕРТИЗЫ}

Анна Александровна Гончарова

Национальная юридическая служба «Амулекс», г. Воронеж, Российская Федерация

Введение: общественная экспертиза представляет собой компетентное участие граждан в управлении делами государства и имеет большой потенциал в области повышения качества принимаемых решений и нормативных правовых актов. Однако в настоящее время заключение по результатам общественной экспертизы носит рекомендательный характер. В связи с этим важно понимать, каково значение заключения по результатам общественной экспертизы. Цель настоящей работы: определить значение заключения по результатам общественной экспертизы, используя идеи делиберативной демократии. Методы: методологическую основу проведенного исследования составляет совокупность методов научного познания, среди которых основное место занимают метод анализа и формально-логический метод. Результаты: выработаны практические рекомендации по совершенствованию правового регулирования общественной экспертизы. Выводы: процедуру общественной экспертизы необходимо дополнить обязательным этапом, на котором будет происходить согласование и обсуждение результатов общественной экспертизы.

Ключевые слова: делиберативная демократия, общественный контроль, общественная экспертиза, независимый эксперт, общественный контроль.

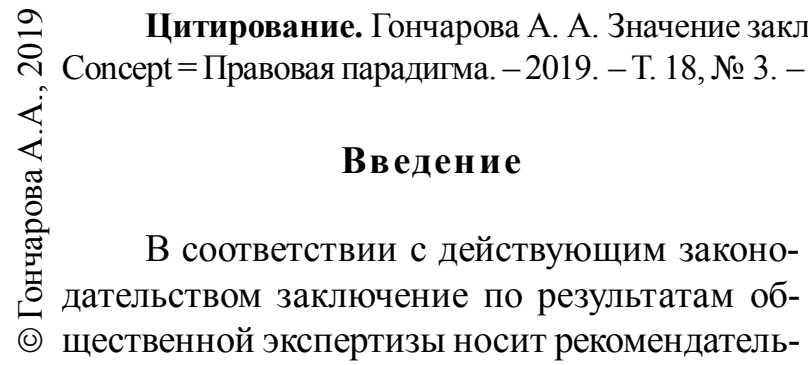

ный характер, поэтому возникает вопрос об определении значения данного документа [1, c. 79]. Изменение статуса заключения по результатам общественной экспертизы и придание ему императивного характера не может 


\section{ТЕОРИЯ И ПРАКТИКА ГОСУДАРСТВЕННО-ПРАВОВОГО РАЗВИТИЯ}

рассматриваться как способ обеспечения учета заключений общественных экспертов при принятии государственно-властных решений. По нашему мнению, рекомендательный характер - единственно возможная характеристика экспертного заключения. Необходимо повышать уровень правосознания и правовой культуры как экспертов, так и государственных и муниципальных служащих, которым предстоит принимать решения с учетом экспертных заключений, а также совершенствовать законодательство в области общественного контроля в целом и общественной экспертизы как его формы. Представляется, что значение заключения по результатам общественной экспертизы может быть раскрыто сквозь призму идей делиберативной демократии.

\section{Делиберативная демократия и общественная экспертиза}

Делиберативную демократию называют также демократией совещательной, дискурсивной. Это направление теории демократии стремится «расширить власть гражданского общества и его влияние на представительную власть и администрацию при помощи процедуры обсуждения, при условии, что дискуссия является «информированной, сбалансированной, сознательной, независимой и всесторонней» [3, с. 57]. Под «дискурсом» в политологии понимается «социальный диалог, происходящий через общественные институты между общественными и политическими акторами» [2, с. 12]. При этом, когда речь идет о делиберативном диалоге, стороны дискурса являются равными [2, с. 13].

Общественная экспертиза как элемент делиберативной демократии позволяет сформулировать мнение общественности и донести его до представителей власти, используя для этого законодательно установленные процедуры. В литературе отмечается, что дискурс может быть диалогичным или монологичным [2, с. 12]. В настоящее время механизм общественной экспертизы, как правило, не дает возможности представителям гражданского общества в режиме диалога с властью отстаивать свою коммуникативную позицию, и в этом видится несовершенство правового регулирова- ния института общественной экспертизы в современной России. Представляется, что дискурс в рамках реализации института общественной экспертизы должен быть диалогичным, а такого качества он может достичь при соответствующем изменении правового регулирования в данной области.

\section{Направления}

\section{совершенствования законодательства}

Необходимо совершенствовать последнюю стадию общественной экспертизы, на которой происходит подготовка экспертного заключения и передача его в уполномоченные органы. В настоящее время заключение по результатам общественной экспертизы передается в уполномоченные властные органы, которые предоставляют субъектам общественного контроля мотивированный ответ. Например, в соответствии с ч. 3 ст. 5 Федерального закона от 17 июля 2009 г. № 172-Ф3 «Об антикоррупционной экспертизе нормативных правовых актов и проектов нормативных правовых актов» по результатам рассмотрения заключения независимых антикоррупционных экспертов гражданину или организации, проводившим независимую экспертизу, направляется мотивированный ответ [4]. Федеральный закон «Об основах общественного контроля в Российской Федерации» содержит положение о том, что уполномоченные органы обязаны рассматривать итоговые документы, подготовленные по результатам общественного контроля, и в установленный законодательством Российской Федерации срок направлять соответствующим субъектам общественного контроля обоснованные ответы [6]. И только ст. 19 Федерального закона от 4 апреля 2005 г. № 32-Ф3 «Об Общественной палате Российской Федерации» предусматривает, что члены Общественной палаты, уполномоченные советом Общественной палаты, приглашаются на заседания соответствующих органов при рассмотрении заключений Общественной палаты по результатам экспертизы проектов соответствующих нормативных правовых актов [5]. Представляется, что только закрепления обязанности рассмотрения заключений общественных экспертов и предоставления 
мотивированного ответа - недостаточно. Что может и должна сделать организация, осуществляющая общественную экспертизу, если содержащиеся в мотивированном ответе доводы не обосновывают должным образом отказ в принятии решения на основании экспертного заключения, либо если по мнению общественных экспертов орган власти неверно трактовал содержащиеся в заключении по результатам общественной экспертизы выводы? Согласно действующему законодательству вся демократическая процедура общественной экспертизы, как правило, заканчивается получением мотивированного ответа. Можем ли мы в такой ситуации говорить о наличии делиберативного диалога и о достижении консенсуса? Представляется, что нет. Решение видится в том, чтобы дополнить процедуру общественной экспертизы обязательным этапом, на котором будет происходить согласование и обсуждение результатов общественной экспертизы, если потребность в таковом возникнет.

\section{Выводы}

Итак, ст. 22 Федерального закона от 4 апреля 2005 г. № 32-Ф3 «Об основах общественного контроля в Российской Федерации» необходимо дополнить частью 11: «Органы государственной власти, органы местного самоуправления, государственные и муниципальные организации, иные органы и организации, осуществляющие в соответствии с федеральными законами отдельные публичные полномочия, обязаны рассмотреть итоговый документ (заключение) по результатам общественной экспертизы, предоставить обоснованный ответ соответствующим субъектам общественного контроля и в случае необходимости провести согласительные процедуры» [6]. Возможность проведения согласительных процедур по результатам общественной экспертизы, вопервых, сделает общественную экспертизу более эффективной, во-вторых, создаст дополнительные гарантии учета общественных интересов при принятии решения, и наконец, поднимет статус общественной экспертизы как формы участия граждан в управлении делами государства.

\section{СПИСОК ЛИТЕРАТУРЫ}

1. Гончарова, А. А. Оценка регулирующего воздействия и общественная экспертиза: соотношение понятий / А. А. Гончарова // Legal Concept = Правовая парадигма. - 2018. - Т. 17, № 3. - С. 7982. -DOI: https://doi.org/10.15688/lc.jvolsu.2018.3.11

2. Котова, А. И. Делиберативная демократия: обзор концепции Ю. Хабермаса / А. И. Котова, В. В. Денисенко // Право: современные тенденции : материалы III Междунар. науч. конф. (г. Краснодар, февраль 2016 г.). - Краснодар : Новация, 2016. C. $10-13$.

3. Линде, А. Н. Делиберативная демократия как направление в современной теории демократии: анализ основных подходов / А. Н. Линде // Контуры глобальных трансформаций: политика, экономика, право. - 2015. - № 1 (39). - С. 52-58.

4. Федеральный закон «Об антикоррупционной экспертизе нормативных правовых актов и проектов нормативных правовых актов» от 17 июля 2009 г. № 172-Ф3 // Собрание законодательства Российской Федерации. - 2009. - № 29. - Ст. 3609.

5. Федеральный закон «Об Общественной палате Российской Федерации» от 4 апреля 2005 г. № 32-Ф3 // Собрание законодательства Российской Федерации. - 2005. - № 15. - Ст. 1277.

6. Федеральный закон «Об основах общественного контроля в Российской Федерации» от 21 июля 2014 г. № 212-Ф3 // Собрание законодательства Российской Федерации. - 2014. - № 30 (ч. I). Ст. 4213.

\section{REFERENCES}

1. Goncharova A. A. Otsenka reguliruyushchego vozdeystviya i obshchestvennaya ekspertiza: sootnoshenie ponyatiy [Regulatory Impact Assessment and Social Expertise: The Ratio of Concepts]. Pravovaya paradigma [Legal Concept], 2018, vol. 17 , no. 3, pp. 79-82. DOI: https://doi.org/ 10.15688/lc.jvolsu.2018.3.11

2. Kotova A.I., Denisenko V.V. Deliberativnaya demokratiya: obzor kontseptsii Yu. Habermasa [Deliberative Democracy: A Review of the Concept of J. Habermas]. Pravo: sovremennye tendentsii: materialy III Mezhdunar. nauch. konf. [Law. Modern Trends. Proceedings of the $3^{\text {rd }}$ International Scientific Conference]. Krasnodar, Novatsiya Publ., 2016, pp. 10-13.

3. Linde A.N. Deliberativnaya demokratiya kak napravlenie $\mathrm{v}$ sovremennoy teorii demokratii: analiz osnovnykh podkhodov [Deliberative Democracy as a Direction in the Modern Theory of Democracy: An Analysis of the Main Approaches]. Kontury globalnykh transformatsiy: politika, ekonomika, pravo, 2015, no. 1 (39), pp. 52-58. 


\section{ТЕОРИЯ И ПРАКТИКА ГОСУДАРСТВЕННО-ПРАВОВОГО РАЗВИТИЯ}

4. Federalnyy zakon «Ob antikorruptsionnoy ekspertize normativnykh pravovykh aktov i proektov normativnykh pravovykh aktov» ot 17 iyulya $2009 \mathrm{~g}$. № 172-FZ [Federal Law “On Anti-Corruption Expertise of Normative Legal Acts and Draft Normative Legal Acts" of 17 July 2009 No. 172-FZ]. Sobraniye zakonodatelstva Rossiyskoy Federatsii [Collected Legislation of the Russian Federation], 2009, no. 29, art. 3609.

5. Federalnyy zakon «Ob Obshchestvennoy palate Rossiyskoy Federatsii» ot 4 aprelya 2005 g. № 32-FZ [The Federal Law “On the Public Chamber of the Russian Federation" of April 4, 2005, no 32-FL]. Sobranie zakonodatelstva Rossiyskoy Federatsii [Collected Legislation of the Russian Federation], 2005, no. 15 , art. 1277.

6. Federalnyy zakon «Ob osnovakh obshchestvennogo kontrolya v Rossiyskoy Federatsii» ot 21 iyulya 2014 g. № 212-FZ [Federal Law "On the Fundamentals of Social Control in the Russian Federation" of July 21, 2014, No. 212-FL]. Sobraniye zakonodatelstva Rossiyskoy Federatsii [Collected Legislation of the Russian Federation], 2014, no. 30 (part 1), art. 4213.

\section{Information about the Author}

Anna A. Goncharova, Leading Specialist, Call Center, "Amuleks" National Legal Service, Moskovsky Prosp., 4, 394026 Voronezh, Russian Federation, anutka3402@yandex.ru, https://orcid.org/ 0000-0002-1198-4733

\section{Информация об авторе}

Анна Александровна Гончарова, ведущий специалист кол-центра, Национальная юридическая служба «Амулекс», Московский просп., 4, 394026 г. Воронеж, Российская Федерация, anutka3402@yandex.ru, https://orcid.org/0000-0002-1198-4733 